\title{
Role of ITGAE in the development of autoimmune diabetes in non-obese diabetic mice
}

\section{Elizabeth S Barrie, Mels Lodder, Paul H Weinreb', Jill Buss, Amer Rajab, Christopher Adin ${ }^{2}$, Qing-Sheng $\mathrm{Mi}^{3}$ and Gregg A Hadley}

The Ohio State University Wexner Medical Center, Room 216 Tzagournis Medical Research Facility, $420 \mathrm{~W}$ 12th Avenue, Columbus, Ohio 43201, USA

${ }^{1}$ Biogen Idec, Cambridge, Massachusetts 02142, USA

${ }^{2}$ College of Veterinary Medicine, Columbus, Ohio 43201 USA

${ }^{3}$ Henry Ford Hospital, Detroit, Michigan 48202, USA
Correspondence should be addressed to G A Hadley

Email

gregg.hadley@osumc.edu

\begin{abstract}
There is compelling evidence that autoreactive $\mathrm{CD} 8^{+} \mathrm{T}$ cells play a central role in precipitating the development of autoimmune diabetes in non-obese diabetic (NOD) mice, but the underlying mechanisms remain unclear. Given that ITGAE (CD103) recognizes an isletrestricted ligand (E-cadherin), we postulated that its expression is required for initiation of disease. We herein use a mouse model of autoimmune diabetes (NOD/ShiLt mice) to test this hypothesis. We demonstrate that ITGAE is expressed by a discrete subset of $C D 8^{+} \mathrm{T}$ cells that infiltrate pancreatic islets before the development of diabetes. Moreover, we demonstrate that development of diabetes in Itgae-deficient NOD mice is significantly delayed at early but not late time points, indicating that ITGAE is preferentially involved in early diabetes development. To rule out a potential contribution by closely linked loci to this delay, we treated WT NOD mice beginning at 2 weeks of age through 5 weeks of age with a depleting anti-ITGAE mAb and found a decreased incidence of diabetes following anti-ITGAE mAb treatment compared with mice that received isotype control mAbs or non-depleting mAbs to ITGAE. Moreover, a histological examination of the pancreas of treated mice revealed that NOD mice treated with a depleting mAb were resistant to immune destruction. These results indicate that $\mathrm{ITGAE}^{+}$cells play a key role in the development of autoimmune diabetes and are consistent with the hypothesis that $\mathrm{ITGAE}^{+} \mathrm{CD} 8^{+} \mathrm{T}$ effectors initiate the disease process.
\end{abstract}
Key Words
- diabetes
- autoimmune
- immune system
mouse

\section{Introduction}

Type 1 diabetes is a T cell-mediated autoimmune disease caused by the destruction of insulin-producing $\beta$ cells of the islets of Langerhans in the pancreas, resulting in a hyperglycemic state. Non-obese diabetic (NOD) mice (NOD/ShiLt) represent an experimental model of type 1 diabetes (Delovitch \& Singh 1997), which mimics key aspects of human disease. Studies of both NOD mice and humans indicate that autoreactive CD4 T cells play a key role in the development of diabetes, in direct destruction of islets and/or in providing help for $\mathrm{B}$ and $\mathrm{T}$ cell responses to islet autoantigens (Shizuru et al. 1988, Haskins \& Cooke 2011). However, there is compelling evidence that recognition of autoantigens by $\operatorname{CD} 8 \alpha \beta^{+} \mathrm{TCR} \alpha \beta^{+}$cells $\left(\mathrm{CD} 8^{+} \mathrm{T}\right.$ cells) plays a pivotal role in the initiation of diabetes. In both diabetic NOD mice and humans, there is evidence that MHC I alleles (the target of CD8 T cells) 
contribute to development of diabetes (Katz et al. 1993, Serreze et al. 1994, Wicker et al. 1994, Serreze et al. 1997, Jarchum et al. 2007, Nejentsev et al. 2007, Tsai et al. 2008). Experiments in which spleen cells from prediabetic NOD mice are transferred into immunodeficient NODSCID recipients document an absolute requirement for CD8 cells in the initial phases of development of diabetes (DiLorenzo et al. 1998). This requirement for CD8 cells is a robust finding reproduced in a variety of experimental models including transfers into non-irradiated young mice (Bendelac et al. 1987), adult irradiated mice (Miller et al. 1988), athymic nude mice (Kano et al. 1992, Matsumoto et al. 1993), and NOD-SCID mice (Christianson et al. 1993, Rohane et al. 1995). Indeed, depletion of CD8 cells in young NOD mice prevents the development of diabetes (Wang et al. 1996). These data are consistent with a model in which autoreactive $\mathrm{CD} 8^{+} \mathrm{T}$ cells initiate the disease process leading to diversification of the CD4 $\mathrm{T}$ cell response and eventual development of a pathogenic CD4 T cell response (Serreze et al. 1997).

$\alpha_{\mathrm{E}}(\mathrm{ITGAE}) / \beta_{7}$ (herein referred to as ITGAE) is a T-cell integrin that confers specificity for the epithelial-cellspecific ligand, E-cadherin (Cepek et al. 1994, Karecla et al. 1995). Results from studies using transplant models indicate that ITGAE promotes destruction of epithelial compartments by alloreactive $\mathrm{CD}^{+} \mathrm{T}$ cells (Feng et al. 2002, El-Asady et al. 2005, Yuan et al. 2005). These findings potentially provide insights into mechanisms of diabetogenesis because the ITGAE ligand, E-cadherin, is highly expressed by pancreatic $\beta$-cells (Cirulli et al. 1994, Meda 2013), the critical targets in diabetes. Several lines of evidence indicate that autoreactive $\mathrm{ITGAE}^{+} \mathrm{CD} 8^{+}$cells play a key role in initiation of diabetes. For instance, ITGAE is preferentially expressed by $\mathrm{CD} 8^{+} \mathrm{T}$ cells (Hadley et al. 1997), a subset thought to play a central role in triggering the development of diabetes. Moreover, $\mathrm{CD} 8^{+} \mathrm{T}$ cells unable to express ITGAE (i.e., from mice with targeted disruption of ITGAE) are deficient in the capacity to reject pancreatic islet allografts (Feng et al. 2002). Histological analyses have revealed that $\mathrm{CD}^{+} \mathrm{T}$ effectors in Itgaedeficient hosts successfully traffic to the general graft site but completely fail to accumulate within the islet allograft itself (Feng et al. 2002). This histological picture is strikingly similar to the peri-insulitis stage in the development of diabetes. Thus, these results raise the possibility that acquisition of expression of ITGAE by diabetogenic CD8 effector/memory cells may be a key checkpoint in progression from peri-insulitis to frank diabetes. Therefore, we postulated that blockade of ITGAE might have the capacity to slow the development of autoimmune diabetes. The goal of this study was to test this hypothesis.

Itgae deficient mice were originally developed in 1999 (Schon et al. 1999) on the Balb/c background. In these mice, exon 10 of the integrin alpha E (Itgae) locus was replaced with a neomycin resistance gene. The deficiency was detected via PCR, fluorescence-activated cell sorting (FACS) analysis, and immunoprecipitation as an insertion of approximately $200 \mathrm{bp}$. Results from previous studies have indicated that Itgae deficiency does not have a significant effect on host weight, reproduction, survival (Schon et al. 1999), or defense against pathogens (Fousteri et al. 2009). In the present studies, the Itgae ${ }^{-1-}$ genotype was backcrossed onto the NOD background. We herein describe the development of Itgae-deficient mice on the NOD background and demonstrate that such mice exhibit delayed development of diabetes. We further document that depleting monoclonal antibodies (mAbs) to ITGAE have a blocking effect in WT NOD mice indicating that the decrease in diabetes development is not due to genes closely linked to Itgae. The interpretation of these results and their therapeutic implications are discussed.

\section{Materials and methods}

\section{PCR}

DNA was isolated from a tail clip using the DNeasy Blood \& Tissue Kit (Qiagen), as per the manufacturer's instructions. The concentration of DNA was measured using a Nanodrop 2000 Spectrophotometer (Thermo Scientific, Waltham, MA, USA). PCR was performed with HotStar Taq Polymerase (Qiagen) on a Veriti Thermocycler (Applied Biosystems). Primers for the detection of Itgae deficiency were as follows: F: GCAACAACGCATCGTTCATATGGA and R: GTGCTCTGTCTATTGTTCCCCTCCTT. The PCR product of the disrupted allele is expected to be $1100 \mathrm{bp}$, while the product for the WT allele is $900 \mathrm{bp}$ (Schon et al. 1999). Primers for the detection of D11Mit320 were as follows: F: CCCATATAGTGAAGCAAGAAACG and R: TTATAGTGTATGCATCCAGGTGTG. Amplification of DNA from NOD mice yields a $124 \mathrm{bp}$ product, whereas mice on a Balb/c background will produce a $140 \mathrm{bp}$ product. Primers for the detection of D11Mit325 were as follows: F: CCTCCACCTGAAAATTCATACT and R: GGTTAGAGGATGATGATGATGATG. Amplification of DNA from NOD mice yields a $110 \mathrm{bp}$ product and a $124 \mathrm{bp}$ product from Balb/c mice.

Published by Bioscientifica Ltd. 


\section{Mice}

NOD/ShiLtJ and Balb/cJ mice were purchased from the Jackson Laboratory (Bar Harboe, ME, USA). To develop Itgae-deficient mice on a diabetic background, we interbred WT NOD mice with Itgae $^{-/-}$mice on the Balb/c background (C.129S2-Itgae $\left.{ }^{\mathrm{tm} 1 \mathrm{Cmp}} / \mathrm{J}\right)$, and then backcrossed the resulting offspring to NOD mice for 12 generations. Diabetes in NOD/ShiLtJ mice is characterized by insulitis, a leukocytic infiltration of the pancreatic islets with marked decreases in pancreatic insulin content occurring in females at approximately 12 weeks of age and several weeks later in males (Makino et al. 1980). Before development of diabetes, blood glucose (BG) levels were tested once per week using a Bayer Glucometer Elite. A mouse was deemed diabetic after two consecutive BG readings of $>250 \mathrm{mg} / \mathrm{dl}$. Mice were housed in accordance with the Ohio State University's requirements and regulations for animal care and use. Mice were maintained under pathogen-free housing conditions with free access to food and water.

\section{Flow cytometry}

Fluorochrome-conjugated $\mathrm{mAbs}$ to mouse ITGAE (2E7 and M290), CD4 (GK1.5), CD8a (53-6,7), CD8b (H35-17.2), CD3e (145-2C11), and CD44 (IM7) and the respective species- and isotype-matched negative control $\mathrm{mAbs}$ were purchased from BD Biosciences Pharmingen (San Jose, CA, USA). Flow cytometry was performed using a FACSCalibur (BD Biosciences) and data were analyzed using the FlowJo Software (BD Bio Sciences Pharmingen). The percentage of positive cells for a given marker was based on cutoff points chosen to exclude $>99 \%$ of the negative control population. Pancreas-infiltrating lymphocytes for flow cytometry experiments were obtained by mincing and then digesting mouse pancreata for $30 \mathrm{~min}$ in DMEM/F12 (50:50) media supplemented with $0.1 \%$ collagenase (type IV; Worthington, Freehold, NJ, USA), 0.1\% soybean trypsin inhibitor (Sigma-Aldrich), and 0.01\% DNase I (Boehringer Mannheim Corp., Indianapolis, IN, USA). Following vigorous agitation, the resulting cell suspension was centrifuged on Lympholyte-M (Accurate Chemical \& Scientific Co., Westbury, NY, USA) to isolate lymphocytes and then stained immediately for analyses.

\section{mAb development and treatment}

The ITGAE mAbs used in these studies were engineered variants of the well-characterized rat anti-mouse ITGAE
mAb, M290 (Kilshaw \& Baker 1988). To produce the mAbs, standard recombinant DNA technology was used to render M290 effector competent in mice by replacing the rat IgG1 Fc domain with a murine IgG2a domain (herein referred to as ChM290-IgG2a), which is anticipated to bind Fc receptors with a high affinity and be an effector competent in mice. To further promote its depleting capacity, ChM290-IgG2a was grown in $\mathrm{CHO}$ cells with targeted disruption of $\alpha 1,2$ fucosyltransferase (Potelligent, Kyowa Hakko Kirin, Tokyo, Japan) that produces a low-fucose antibody, which has been shown to improve Fc receptor binding and enhance effector function (Shinkawa et al. 2003). For a blocking but nondepleting mAb, we generated a variant (ChM290-IgG1) that contains the same antigen-binding regions as ChM290-IgG2a but carries an IgG1 Fc domain. A specific point mutation (at position N297Q, Kabat numbering) was introduced within the murine IgG1 constant domain to eliminate the $N$-glycosylation site, rendering the mAb essentially unable to bind Fc receptors and recruit effector cells (Jefferis 2009). Starting at 2 weeks of age, we treated NOD pups with ChM290-IgG2a afucosyl $(n=13)$ or ChM290-IgG1 agly $(n=16)$ at $1 \mathrm{mg} / \mathrm{kg}$ i.p. once per week through 5 weeks of age. The dose of antibody was determined empirically by measuring the in vivo dose of M290 required to block adhesion of mouse primary lymphocytes to an E-cadherin Fc fusion protein. At a dose of $1 \mathrm{mg} / \mathrm{kg}$, the predicted peak serum concentration was in the range of $10-100 \mu \mathrm{g} / \mathrm{ml}$, well above this value. As a negative control, a group of NOD pups $(n=17)$ were treated in parallel with P1.17, a mouse Ig2a isotype control antibody of irrelevant specificity (Neuwelt et al. 1994, Remsen et al. 1996, Metzner et al. 2005). As determination of sex was not possible at the initial time of injection ( 2 weeks of age), all pups were treated with the respective reagent, and once sex was determined males were killed. BG levels were then measured through 30 weeks twice weekly (unless the mouse developed diabetes at an earlier time point) with diabetes defined as two consecutive readings $>250 \mathrm{mg} / \mathrm{dl}$ BG. Serum and pancreas were collected following diabetes development.

\section{Statistical analyses}

A Kaplan-Meier analysis was performed using GraphPad Prism (La Jolla, CA, USA) and significance of pairwise comparisons calculated by the log rank (Mantel-Cox) test using the SPSS Software (IBM, Armonk, NY, USA). A value of $P<0.05$ was considered to be statistically significant.

Published by Bioscientifica Ltd. 


\section{Results}

\section{Expression of ITGAE by $\mathrm{CD}^{+} \mathrm{T}$ cells in the NOD pancreas during development of diabetes}

To determine the extent to which ITGAE is expressed by CD8 cells during the course of diabetes, we conducted FACS analyses of lymphocytes isolated from the pancreata, lymph nodes (LNs), and spleens of female NOD mice at different points in disease progression. In these experiments, we monitored ITGAE expression by $\mathrm{CD}^{+} \mathrm{T}$ cells of effector/memory phenotype (gated CD8b ${ }^{+} \mathrm{CD} 44^{\text {hi }}$ cells) beginning at 7 weeks through development of hyperglycemia, which occurred at 17 weeks of age (on average) in our colony. ITGAE expression is constant in spleen and LNs over time. There is a drop in ITGAE expression in pancreas-infiltrating lymphocytes at week 10.5 , with a return to previous levels by the final time point. Small numbers of $\mathrm{CD} 8 \mathrm{~b}^{+} \mathrm{CD} 44^{\text {hi }} \mathrm{T}$ cells $\left(0.2 \times 10^{6}\right.$ cells/pancreas) were present in the pancreas of female NOD mice as early as 7 weeks of age and the total number increased progressively with age, reaching maximal numbers at the time of overt diabetes (BG $>250 \mathrm{mg} / \mathrm{dl}$ ) $\left(0.5 \times 10^{6}\right.$ cells/pancreas $)$. As shown in Fig. 1, ITGAE was expressed by a subset of CD8 T effectors $\left(C D 8{ }^{+} C D 44^{\text {hi }}\right.$ cells) at all time points examined. These data are consistent with a role for the $\mathrm{ITGAE}^{+} \mathrm{CD}^{+}$effector/ memory subset in transition from benign peri-insulitis to invasive insulitis. Note that while the proportion of $\mathrm{CD}^{+} \mathrm{CD} 44^{\text {hi }}$ cells expressing ITGAE is relatively small, this percentage is similar to that of $\mathrm{CD}^{+} \mathrm{T}$ cells isolated from rejected pancreatic islet allografts, a scenario where

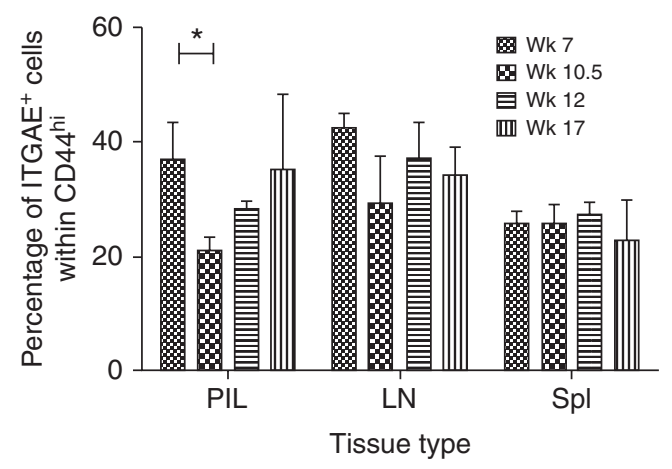

Figure 1

ITGAE expression by gated CD8b ${ }^{+}$CD44 ${ }^{\text {hi }}$ lymphocytes isolated from pancreata (PIL), lymph nodes (LN), and spleens (Spl) of female NOD mice of the indicated ages and stages of diabetes development $(n=3)$. Cells are stained with mAbs to CD8b (H35-17.2) and CD44 in combination with mAbs to ITGAE (M290). All mice at week 17 are hyperglycemic.
$\mathrm{ITGAE}^{+} \mathrm{CD}^{+} \mathrm{T}$ cells play a critical role in $\beta$-cell destruction (Feng et al. 2002).

\section{Itgae deficiency delays the development of type 1 diabetes}

To test the hypothesis that autoreactive $\mathrm{ITGAE}^{+} \mathrm{CD}{ }^{+}$ effector/memory cells play a pivotal role in triggering diabetes development, we compared the incidence of diabetes in NOD mice homozygous for the Itgae knockout allele with that of WT NOD littermates. For this, backcross offspring were monitored for the presence of the Itgae knockout allele, which as shown in Fig. 2A, is readily distinguished from the WT allele by standard PCR methodology. Only mice with two disrupted copies of Itgae were included in this study. Moreover, only females were used in these experiments because of the earlier development and higher incidence of diabetes when compared with male mice. To confirm the absence of the ITGAE protein, lymphocytes infiltrating the host pancreas were stained for ITGAE expression (Fig. 2D).

The Itgae locus is located at $45.22 \mathrm{cM}$ on mouse chromosome 11 (MGI website). To confirm that the mice were on the NOD background, we genotyped two marker sites that differed between NOD and Balb/c, flanking Itgae. Figure $2 \mathrm{~B}$ shows that the NOD-Itgae ${ }^{-/-}$mice expressed the NOD allele at the D11Mit320 locus (43.21 cM) and Fig. 2C demonstrates that the knockout mice expressed the NOD allele at the D11Mit325 locus $(51.88 \mathrm{cM})$. The presence of the NOD allele at D11Mit320 and D11Mit325 provided compelling evidence that the resulting strain was predominantly of NOD origin. As shown in Fig. 2D, NOD-Itgae $e^{-/-}$mice completely failed to express ITGAE, whereas samples from WT NOD mice contained readily detectable populations of ITGAE-expressing $\mathrm{CD}^{+}$and $\mathrm{CD}^{-} \mathrm{T}$ cells.

As shown in Fig. 3, Itgae $e^{-/-}$mice on the NOD background (open circles, $n=60$ ) were delayed by 5-6 weeks in the development of diabetes when compared with WT NOD littermates (filled circles, $n=42)(3 \%$ incidence for knockout when compared with $43 \%$ for WT mice at 20 weeks). While the greatest effects of Itgae deficiency on development of diabetes were observed at early time points (weeks 17-21), the difference persisted through to the end of the observation period. There was a strong significant difference between the Itgae $^{-/-}$and WT groups $\left(P=8 \times 10^{-9}\right)$. These results indicated that the absence of ITGAE delays development of diabetes in NOD mice but does not prevent development of diabetes,

Published by Bioscientifica Ltd 

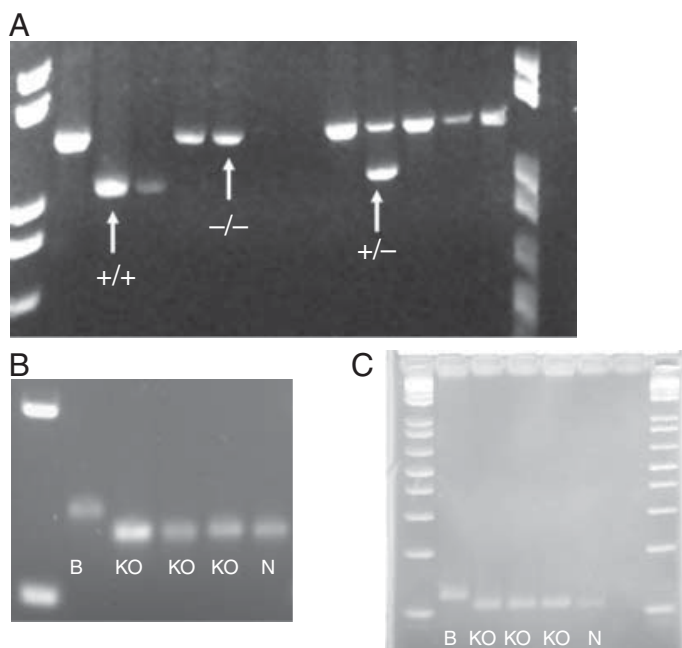

D

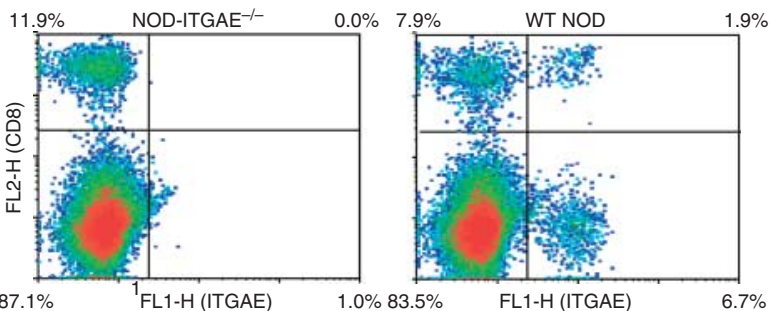

Figure 2

Development and characterization of Itgae-deficient NOD mice. (A) Expression of ITGAE by backcross offspring. Genomic DNA from backcross offspring was amplified with primers to Itgae. Data presented are obtained from a typical screening assay to detect backcross offspring carrying the Itgae KO allele. Lanes 1 and 12 are DNA ladders. Lane 2: Balb/c-Itgae ${ }^{-1-}$; Lane 3: WT Balb/c; Lane 4: WT NOD; Lanes 5-11: 12th generation backcross offspring. The three possible genotypes are indicated by arrows. Lane 3 shows two copies of the WT allele $(+/+)$; lane 6 shows a full knockout with two disrupted copies of Itgae $(-/-)$; lane 10 shows a mouse carrying one copy of the WT allele and one disrupted allele $(+/-)$. The PCR product for the disrupted allele is expected to be $1100 \mathrm{bp}$, while the product for the WT allele is $900 \mathrm{bp}$. (B). Genomic DNA amplified with Mit320 primers. Lane 1: DNA ladder; lane 2: Balb/c (B); lanes 3-5: 12th generation NOD-Itgae ${ }^{-1-}$ (KO); lane 6: WT NOD (N). In this assay, a mouse on a Balb/c background shows a band at $140 \mathrm{bp}$, while the other on a NOD background shows a band at $124 \mathrm{bp}$. (C) Genomic DNA amplified with Mit325 primers. Lanes 1 and 8 contain DNA ladder; Lane 2: WT Balb/c (B); Lanes 3-5: 12th generation NOD-Itgae ${ }^{-1-}$ (KO); Lane 6: WT NOD (N); Lane 7: no-template control. Samples on a NOD background amplify a $110 \mathrm{bp}$ product, while those on a Balb/c background amplify a product of $124 \mathrm{bp}$. (D) 2D FACS density plot of CD8 versus ITGAE expression of gated $C D 3^{+}$pancreasinfiltrating lymphocytes from a representative NOD-Itgae knockout mouse (left) when compared with a WT NOD mouse (right).

indicating that expression of ITGAE is not absolutely required for development of diabetes in the NOD mouse.

\section{Treatment of WT NOD pups with depleting mAbs to ITGAe decreases the incidence of diabetes}

It remained possible that the delayed development of diabetes in Cd103-deficient hosts reflected the action of non ITGAE encoded loci mapping close to Itgae. We have previously reported that the existing mAbs to murine ITGAE are non-depleting and that our anti-ITGAE immunotoxin is extremely hepatotoxic (Zhang et al. 2009). In the present studies, we developed a ITGAEdepleting $\mathrm{mAb}$ that lacks the extreme hepatotoxicity of our anti-ITGAE immunotoxin. As shown in Fig. 4, ChM290-IgG2a afucosyl was highly effective at eliminating $\mathrm{ITGAE}^{+} \mathrm{CD}^{+} \mathrm{T}$ cells from the small intestinal epithelia and spleens of 8-week-old NOD mice given a single injection at a dose of $1 \mathrm{mg} / \mathrm{kg}$. In contrast, ChM290-IgG1 agly was completely ineffectual in this regard with levels of $\mathrm{ITGAE}^{+} \mathrm{CD}^{+} \mathrm{T}$ cells in the spleens and intraepithelial lymphocyte compartments similar to those of NOD mice treated with the isotype control mAb, P1.17. Notably, a second anti-mouse ITGAE mAb, 2E7 - which is directed to an independent ITGAE epitope (Lefrancois et al. 1994) was used for detection of ITGAE in these experiments, hence the absence of ITGAE-expressing cells was not due to masking of the determinant by residual mAbs. Based on these results, we conclude that ChM290-IgG2a afucosyl depletes ITGAE-expressing cells in NOD mice.

We then used this antibody to deplete ITGAEexpressing cells in female WT NOD mice and monitored the development of diabetes through 30 weeks of age. Treatment began at 2 weeks of age, with a weekly injection through to week 5 (four injections in total). The three groups included were as follows: ChM290-IgG2a afucosyl (depleting, $n=13$ ), ChM290-IgG1 aglycosylated (agly) (non-depleting, $n=16$ ), and isotype control (P1.17, IgG2a, $n=17)$.

Results presented in Figure 5 indicate that treatment with ChM290-IgG2a decreased the incidence of diabetes compared with ChM290-IgG1 or the isotype-matched negative control mAb (P1.17, IgG2a). Although the pairwise comparison between development of diabetes in the WT and IgG2a treatment groups did not display a

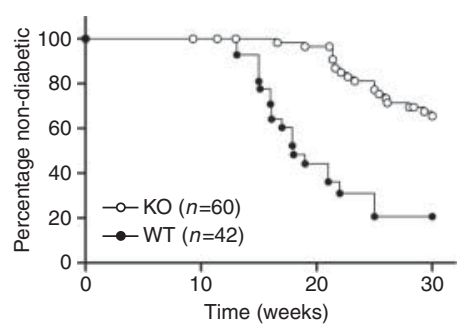

\section{Figure 3}

Incidence of diabetes in NOD-Itgae ${ }^{-1-}$ mice (open circles, $n=60$ ), vs WT NOD mice (filled circles, $n=42$ ). Blood glucose levels were measured once per week via tail vein laceration. Both the 12th generation backcross NOD-Itgae ${ }^{-I-}$ offspring and WT NOD mice were bred in-house. 


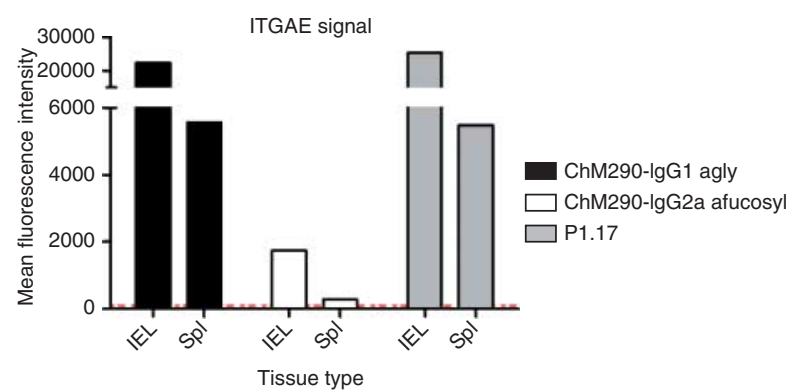

Figure 4

FACS analysis of depletion of $\mathrm{ITGAE}^{+}$(gated on $\mathrm{CD}^{+}, \mathrm{CD}^{+}$cells) intraepithelial lymphocytes (IELs) and splenic lymphocytes (Spl) in 8-weekold NOD mice following a single i.p. injection of the following at $1 \mathrm{mg} / \mathrm{kg}$ : aglycosylated ChM90-IgG1, afucosylated ChM90-IgG2a, or an isotypematched negative control mAb (P1.17, mlgG2a). After 4 days, lymphocytes were harvested and stained as described previously (Zhang et al. 2009).

statistically significant difference, there was a trend toward significance $(P=0.07)$, reflecting a decreased incidence of diabetes in the IgG2a-treated group compared with untreated mice.

While we have demonstrated an effect of treatment at weeks 2 and 8 , later-stage treatment was ineffective. We treated mice $(n=3)$ aged 16 weeks with injections of either ChM290-IgG2a afucosyl or P1.17. By week 20, two mice in the IgG2a group and one in the P1.17 group had developed diabetes.

A histological examination of the insulin-producing cells in the various groups revealed that mice treated with depleting mAbs to ITGAE (ChM290-IgG2a afucosyl) were resistant to destruction of cells by islet-infiltrating leukocytes as evidenced by a lack of injury to the insulin-producing cells (Fig. 6A and B). This histology was highly similar to that of mice treated with the isotype control mAb (P1.17) that failed to develop autoimmune diabetes (Fig. 6C and D). Notably, the pancreata of both mice exhibited the hallmark characteristics of autoimmune diabetes with massive infiltration of residual insulin-producing cells of the pancreas ( $\beta$ cells) with leukocytes. In diabetic mice treated with ChM290-IgG1 agly or the isotype control $\mathrm{mAb}$, the insulin-producing cells were completely destroyed and thus they did not display residual cells (results not shown). These data provide direct evidence that depletion of ITGAE-expressing cells can moderate the course of autoimmune diabetes.

\section{Discussion}

We herein provide evidence that $\mathrm{ITGAE}^{+} \mathrm{CD} 8^{+} \mathrm{T}$ effectors initiate the development of autoimmune diabetes in
NOD mice. We initially determined that ITGAE is expressed by $\mathrm{CD}^{+} \mathrm{T}$ effectors before the onset of disease in these mice (Fig. 1). Our results further indicate that NOD-Itgae knockout mice exhibit a significant delay in development of autoimmune diabetes (Fig. 3). We use a ITGAE-depleting $\mathrm{mAb}$ to exclude the possibility that this delay represents an effect of one or more of the large number of loci known to confer protection from diabetes (Fig. 4), some of which map to sites in close proximity to Itgae. Indeed, Itgae maps within the Idd4.2 locus (Ivakine et al. 2006), hence it was important to perform studies with a ITGAE-depleting $\mathrm{mAb}$ to exclude the possibility that the delayed development of diabetes was due to carryover of closely linked genes during backcrossing. We observed the strongest effect in the Itgae knockout mice, but a depleting anti-ITGAE mAb (ChM90-IgG2a afucosyl) also decreased the development of diabetes in WT NOD mice and protected insulin-producing cells from immune destruction, strongly indicating that the effects are due to Itgae itself.

It is not clear why targeted disruption of ITGAE on the NOD background was more effective than depletion of ITGAE-expressing cells from WT hosts at preventing the onset of diabetes. There are many potential technical explanations for this including the difference between the constitutive absence of ITGAE from birth in NOD-Itgae $^{-/-}$mice versus elimination of pre-existing ITGAE $^{+}$cells from WT NOD mice and an immune response to the antibodies, thereby neutralizing their effectiveness Although the constant regions of ChM20IgG2a are of mouse origin and are therefore probably

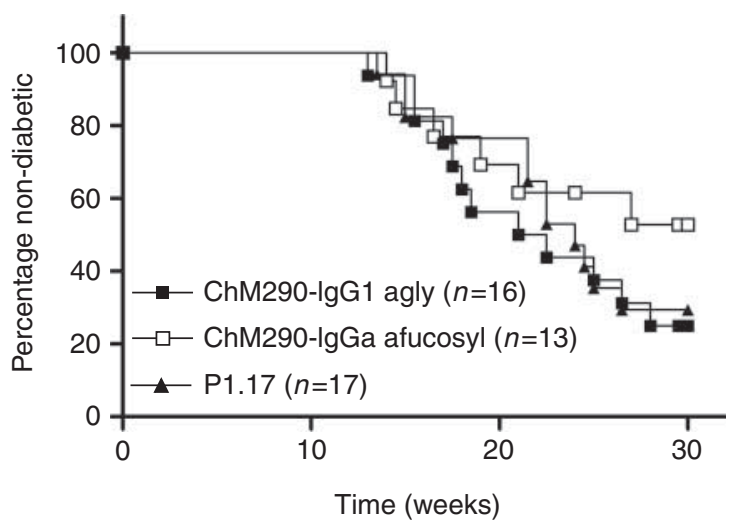

Figure 5

Incidence of diabetes in WT NOD mice treated with murinized anti-ITGAE $m A b s$ engineered to express either an afucosylated IgG2a (open squares, $n=13$, ChM290-IgG2a) or aglycosylated IgG1 (filled squares, $n=16$, chM290-lgG1 agly) Fc domain. A control group was treated with an isotypematched negative control mAb (filled triangles, $n=17, \mathrm{P} 1.17, \lg \mathrm{G} 2 \mathrm{a}$ ). Mice received injections from 2 through 5 weeks of age of an mAb at a dose of $1 \mathrm{mg} / \mathrm{kg}$. 


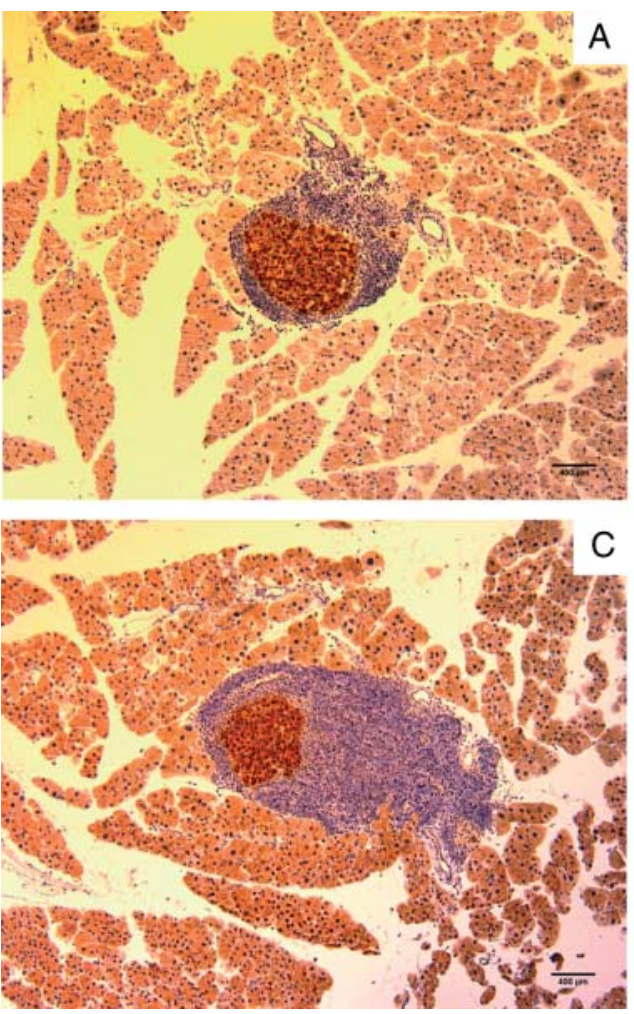

Figure 6

Immunohistochemistry of a pancreas from a diabetic mouse treated with ChM290-IgG2a afucosyl (A and B). As a control, similar sections from a non-diabetic NOD mouse treated with an isotype control mAb, P1.17, are shown (C and D). Insulin-producing cells are stained dark brown with

non-immunogenic, the variable regions are still of rat origin and are thus potentially immunogenic.

In addition to CD8 $\mathrm{T}$ cells, ITGAE is potentially expressed by diverse leukocyte populations with important effector and regulatory functions, including dendritic cells (Fujimoto et al. 2011) and regulatory T cells (T regs) (Lehmann et al. 2002). Therefore, our results do not exclude the possibility that the latter cell populations contribute to the observed effects. ITGAE defines a subset of $\mathrm{CD} 4{ }^{+} \mathrm{CD} 25^{+} \mathrm{T}$ regs in the gut that exhibit potent immunosuppressive activity in vitro (Lehmann et al. 2002, Chen et al. 2008). Moreover, there is compelling evidence that the initiation of diabetes is controlled by $\mathrm{T}$ regs (You et al. 2008). However, our results indicating that neither elimination of ITGAE expression by gene knockout (Fig. 3) nor depletion of ITGAE-expressing cells (Fig. 4) increases the incidence of diabetes in NOD mice indicate that $\mathrm{ITGAE}^{+} \mathrm{T}$ regs do not contribute to this process. While there is evidence of a role for ITGAE-expressing dendritic cells in controlling the development of ITGAE-expressing $T$ regs (Annacker et al. 2005), our results indicate that this

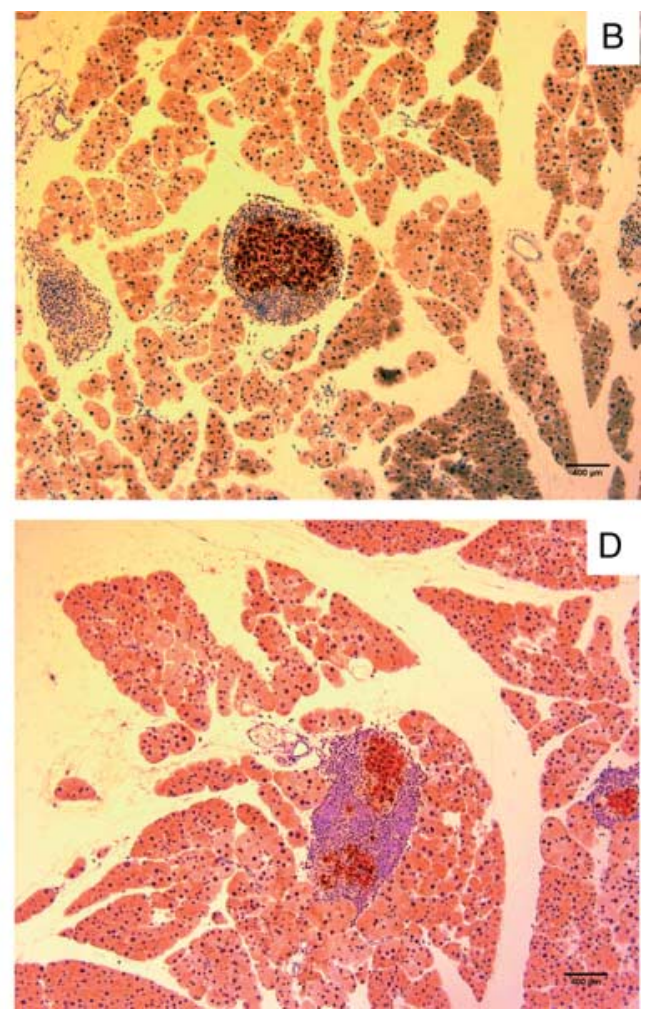

an anti-insulin $\mathrm{Ab}$ followed by diaminobenzidine (DAB); sections are counterstained (blue) with hematoxylin to highlight infiltrating leukocytes. Scale bars $400 \mu \mathrm{m}$.

pathway is not operative during development of autoimmune diabetes in NOD mice. Rather, we proposed that the control of autoimmune diabetes is mediated by the $\mathrm{ITGAE}^{-}$subset of T regs. To explain the transient delay in autoimmune diabetes observed in NOD-Itgae ${ }^{-/-}$mice, we postulate that ITGAE expressed by CD8 T cells is required for initiation of diabetes, whereas at later time points the ITGAE-negative subset of $\mathrm{T}$ regs suppress this effect; leading to a biphasic requirement for expression of ITGAE during development of diabetes. However, as noted earlier in this study, our data do not exclude the possibility of a contribution by ITGAE-expressing dendritic cells to the development of autoimmune diabetes.

In summary, the expression of ITGAE by $\mathrm{CD} 8^{+} \mathrm{T}$ cells that infiltrate the pancreatic islets before the development of diabetes (Fig. 1) indicated that blockade of ITGAE might be used to delay the onset of autoimmune diabetes, and our findings are consistent with this possibility (Figs 3 and 5). Our results indicating that Itgae-deficient hosts ultimately develop diabetes indicate that depleting antibodies to ITGAE may be ineffective in preventing

Published by Bioscientifica Lto. 
disease per se, but may be useful in inhibiting insulitis and thereby slowing the progression of the disease.

\section{Declaration of interest}

P H W is an employee and shareholder of Biogen Idec, Inc.; none of the other authors have a conflict of interest.

\section{Funding}

This work was supported in part by funding from the National Institutes of Health-R01-Al036532.

\section{Author contribution statement}

E S B wrote the manuscript and researched data. $M L$ researched data. $\mathrm{PH} \mathrm{W}$ researched data and contributed to the discussion. J B researched data. A R contributed to the discussion. C A contributed to the discussion. $\mathrm{Q} \mathrm{M}$ researched data and contributed to the discussion. $\mathrm{G} \mathrm{A} \mathrm{H}$ wrote the manuscript and has access to all presented data and will take responsibility for the integrity of all data; he therefore is the guarantor of the study.

\section{Acknowledgements}

The authors would like to thank Bryan Anthony and Jiao-Jing Wang for their technical assistance and scientific discussion. They are also grateful to Mary Gemmel and Rebecca Ita for treating NOD pups with mAbs, and to Li Zhou for genotyping the backcross offspring.

\section{References}

Annacker O, Coombes JL, Malmstrom V, Uhlig HH, Bourne T, JohanssonLindbom B, Agace WW, Parker CM \& Powrie F 2005 Essential role for CD103 in the T cell-mediated regulation of experimental colitis. Journal of Experimental Medicine 202 1051-1061. (doi:10.1084/jem. 20040662)

Bendelac A, Carnaud C, Boitard C \& Bach JF 1987 Syngeneic transfer of autoimmune diabetes from diabetic NOD mice to healthy neonates. Requirement for both $\mathrm{L} 3 \mathrm{~T} 4{ }^{+}$and Lyt- $2^{+} \mathrm{T}$ cells. Journal of Experimental Medicine 166 823-832. (doi:10.1084/jem.166.4.823)

Cepek KL, Shaw SK, Parker CM, Russell GJ, Morrow JS, Rimm DL \& Brenner MB 1994 Adhesion between epithelial cells and T lymphocytes mediated by E- cadherin and the $\alpha_{\mathrm{E}} \beta_{7}$ integrin. Nature 372 190-193. (doi:10.1038/372190a0)

Chen X, Subleski JJ, Kopf H, Howard OM, Mannel DN \& Oppenheim JJ 2008 Cutting edge: expression of TNFR2 defines a maximally suppressive subset of mouse $\mathrm{CD} 4{ }^{+} \mathrm{CD} 25^{+} \mathrm{FoxP} 3^{+} \mathrm{T}$ regulatory cells: applicability to tumor-infiltrating $\mathrm{T}$ regulatory cells. Journal of Immunology 180 6467-6471. (doi:10.4049/jimmunol.180.10.6467)

Christianson SW, Shultz LD \& Leiter EH 1993 Adoptive transfer of diabetes into immunodeficient NOD-scid/scid mice. Relative contributions of $\mathrm{CD}^{+}{ }^{+}$and $\mathrm{CD}^{+}$T-cells from diabetic versus prediabetic NOD.NONThy- $1^{\text {a }}$ donors. Diabetes 42 44-55. (doi:10.2337/diab.42.1.44)

Cirulli V, Baetens D, Rutishauser U, Halban PA, Orci L \& Rouiller DG 1994 Expression of neural cell adhesion molecule (N-CAM) in rat islets and its role in islet cell type segregation. Journal of Cell Science $\mathbf{1 0 7}$ 1429-1436.

Delovitch TL \& Singh B 1997 The nonobese diabetic mouse as a model of autoimmune diabetes: immune dysregulation gets the NOD. Immunity 7 727-738. (doi:10.1016/S1074-7613(00)80392-1)
DiLorenzo TP, Graser RT, Ono T, Christianson GJ, Chapman HD, Roopenian DC, Nathenson SG \& Serreze DV 1998 Major histocompatibility complex class I-restricted T cells are required for all but the end stages of diabetes development in nonobese diabetic mice and use a prevalent T cell receptor $\alpha$ chain gene rearrangement. PNAS 95 12538-12543. (doi:10.1073/pnas.95.21.12538)

El-Asady R, Yuan R, Liu K, Wang D, Gress RE, Lucas PJ, Drachenberg CB \& Hadley GA 2005 TGF- $\beta$-dependent CD103 expression by CD8 ${ }^{+}$T cells promotes selective destruction of the host intestinal epithelium during graft-versus-host disease. Journal of Experimental Medicine 201 1647-1657. (doi:10.1084/jem.20041044)

Feng Y, Wang D, Yuan R, Parker CM, Farber DL \& Hadley GA 2002 CD103 expression is required for destruction of pancreatic islet allografts by $\mathrm{CD}^{+}{ }^{+} \mathrm{T}$ cells. Journal of Experimental Medicine 196 877-886. (doi:10.1084/jem.20020178)

Fousteri G, Dave A, Juntti T \& von Herrath M 2009 CD103 is dispensable for anti-viral immunity and autoimmunity in a mouse model of virallyinduced autoimmune diabetes. Journal of Autoimmunity 32 70-77. (doi:10.1016/j.jaut.2008.12.001)

Fujimoto K, Karuppuchamy T, Takemura N, Shimohigoshi M, Machida T, Haseda Y, Aoshi T, Ishii KJ, Akira S \& Uematsu S 2011 A new subset of $\mathrm{CD}_{103}{ }^{+} \mathrm{CD} 8 \alpha^{+}$dendritic cells in the small intestine expresses TLR3, TLR7, and TLR9 and induces Th1 response and CTL activity. Journal of Immunology 186 6287-6295. (doi:10.4049/jimmunol.1004036)

Hadley GA, Bartlett ST, Via CS, Rostapshova EA \& Moainie S 1997 The epithelial cell-specific integrin, CD103 (alpha E integrin), defines a novel subset of alloreactive CD8 ${ }^{+}$CTL. Journal of Immunology 159 3748-3756.

Haskins K \& Cooke A 2011 CD4 T cells and their antigens in the pathogenesis of autoimmune diabetes. Current Opinion in Immunology 23 739-745. (doi:10.1016/j.coi.2011.08.004)

Ivakine EA, Mortin-Toth SM, Gulban OM, Valova A, Canty A, Scott C \& Danska JS 2006 The idd4 locus displays sex-specific epistatic effects on type 1 diabetes susceptibility in nonobese diabetic mice. Diabetes $\mathbf{5 5}$ 3611-3619. (doi:10.2337/db06-0758)

Jarchum I, Baker JC, Yamada T, Takaki T, Marron MP, Serreze DV \& DiLorenzo TP 2007 In vivo cytotoxicity of insulin-specific CD8 ${ }^{+}$T-cells in HLA-A*0201 transgenic NOD mice. Diabetes 56 2551-2560. (doi:10.2337/db07-0332)

Jefferis R 2009 Recombinant antibody therapeutics: the impact of glycosylation on mechanisms of action. Trends in Pharmacological Sciences 30 356-362. (doi:10.1016/j.tips.2009.04.007)

Kano T, Shimoda O, Morioka T, Yagishita Y \& Hashiguchi A 1992 Evaluation of the central nervous function in resuscitated comatose patients by multilevel evoked potentials. Resuscitation 23 235-248. (doi:10.1016/0300-9572(92)90007-Y)

Karecla PI, Bowden SJ, Green SJ \& Kilshaw PJ 1995 Recognition of E-cadherin on epithelial cells by the mucosal T cell integrin $\alpha_{\mathrm{M} 290} \beta_{7}$ ( $\alpha \mathrm{E} \beta 7$ ). European Journal of Immunology 25 852-856. (doi:10.1002/eji. 1830250333)

Katz J, Benoist C \& Mathis D 1993 Major histocompatibility complex class I molecules are required for the development of insulitis in non-obese diabetic mice. European Journal of Immunology 23 3358-3360. (doi:10.1002/eji.1830231244)

Kilshaw PJ \& Baker KC 1988 A unique surface antigen on intraepithelial lymphocytes in the mouse. Immunology Letters 18 149-154. (doi:10.1016/0165-2478(88)90056-9)

Lefrancois L, Barrett TA, Havran WL \& Puddington L 1994 Developmental expression of the $\alpha_{\mathrm{IEL}} \beta_{7}$ integrin on T cell receptor $\gamma \delta$ and T cell receptor $\alpha \beta$ T cells. European Journal of Immunology 24 635-640. (doi:10.1002/eji. 1830240322)

Lehmann J, Huehn J, de la Rosa M, Maszyna F, Kretschmer U, Krenn V, Brunner M, Scheffold A \& Hamann A 2002 Expression of the integrin $\alpha_{\mathrm{E}} \beta_{7}$ identifies unique subsets of $\mathrm{CD} 25^{+}$as well as $\mathrm{CD} 25^{-}$regulatory T cells. PNAS 99 13031-13036. (doi:10.1073/pnas.192162899) 
Makino S, Kunimoto K, Muraoka Y, Mizushima Y, Katagiri K \& Tochino Y 1980 Breeding of a non-obese, diabetic strain of mice. Jikken Dobutsu. Experimental Animals 29 1-13.

Matsumoto M, Yagi H, Kunimoto K, Kawaguchi J, Makino S \& Harada M 1993 Transfer of autoimmune diabetes from diabetic NOD mice to NOD athymic nude mice: the roles of $\mathrm{T}$ cell subsets in the pathogenesis. Cellular Immunology 148 189-197. (doi:10.1006/cimm.1993.1101)

Meda P 2013 Protein-mediated interactions of pancreatic islet cells. Scientifica 2013 621249. (doi:10.1155/2013/621249)

Metzner KJ, Moretto WJ, Donahoe SM, Jin X, Gettie A, Montefiori DC, Marx PA, Binley JM, Nixon DF \& Connor RI 2005 Evaluation of CD8 ${ }^{+}$ T-cell and antibody responses following transient increased viraemia in rhesus macaques infected with live, attenuated simian immunodeficiency virus. Journal of General Virology 86 3375-3384. (doi:10.1099/ vir.0.81206-0)

Miller BJ, Appel MC, O'Neil JJ \& Wicker LS 1988 Both the Lyt-2 ${ }^{+}$and $\mathrm{L} 3 \mathrm{~T}^{+}{ }^{+} \mathrm{T}$ cell subsets are required for the transfer of diabetes in nonobese diabetic mice. Journal of Immunology 140 52-58.

Nejentsev S, Howson JM, Walker NM, Szeszko J, Field SF, Stevens HE, Reynolds P, Hardy M, King E, Masters J et al. 2007 Localization of type 1 diabetes susceptibility to the MHC class I genes $H L A-B$ and $H L A-A$. Nature 450 887-892. (doi:10.1038/nature06406)

Neuwelt EA, Barnett PA, Hellstrom KE, Hellstrom I, McCormick CI \& Ramsey FL 1994 Effect of blood-brain barrier disruption on intact and fragmented monoclonal antibody localization in intracerebral lung carcinoma xenografts. Journal of Nuclear Medicine 35 1831-1841.

Remsen LG, McCormick CI, Roman-Goldstein S, Nilaver G, Weissleder R, Bogdanov A, Hellstrom I, Kroll RA \& Neuwelt EA 1996 MR of carcinoma-specific monoclonal antibody conjugated to monocrystalline iron oxide nanoparticles: the potential for noninvasive diagnosis. AJNR. American Journal of Neuroradiology 17 411-418.

Rohane PW, Shimada A, Kim DT, Edwards CT, Charlton B, Shultz LD \& Fathman CG 1995 Islet-infiltrating lymphocytes from prediabetic NOD mice rapidly transfer diabetes to NOD-scid/scid mice. Diabetes $\mathbf{4 4}$ 550-554. (doi:10.2337/diab.44.5.550)

Schon MP, Arya A, Murphy EA, Adams CM, Strauch UG, Agace WW, Marsal J, Donohue JP, Her H, Beier DR et al. 1999 Mucosal T lymphocyte numbers are selectively reduced in integrin $\alpha_{\mathrm{E}}$ (CD103)-deficient mice. Journal of Immunology 162 6641-6649.
Serreze DV, Leiter EH, Christianson GJ, Greiner D \& Roopenian DC 1994 Major histocompatibility complex class I-deficient NOD- $B 2 m^{\text {null }}$ mice are diabetes and insulitis resistant. Diabetes 43 505-509. (doi:10.2337/ diab.43.3.505)

Serreze DV, Chapman HD, Varnum DS, Gerling I, Leiter EH \& Shultz LD 1997 Initiation of autoimmune diabetes in NOD/Lt mice is MHC class Idependent. Journal of Immunology 158 3978-3986.

Shinkawa T, Nakamura K, Yamane N, Shoji-Hosaka E, Kanda Y, Sakurada M, Uchida K, Anazawa H, Satoh M, Yamasaki M et al. 2003 The absence of fucose but not the presence of galactose or bisecting $\mathrm{N}$-acetylglucosamine of human IgG1 complex-type oligosaccharides shows the critical role of enhancing antibody-dependent cellular cytotoxicity. Journal of Biological Chemistry 278 3466-3473. (doi:10.1074/jbc.M210665200)

Shizuru JA, Taylor-Edwards C, Banks BA, Gregory AK \& Fathman CG 1988 Immunotherapy of the nonobese diabetic mouse: treatment with an antibody to T-helper lymphocytes. Science 240 659-662. (doi:10.1126/ science.2966437)

Tsai S, Shameli A \& Santamaria P $2008 \mathrm{CD}^{+}$T cells in type 1 diabetes. Advances in Immunology 100 79-124. (doi:10.1016/S0065-2776(08) 00804-3)

Wang B, Gonzalez A, Benoist C \& Mathis D 1996 The role of CD8 ${ }^{+}$T cells in the initiation of insulin-dependent diabetes mellitus. European Journal of Immunology 26 1762-1769. (doi:10.1002/eji.1830260815)

Wicker LS, Leiter EH, Todd JA, Renjilian RJ, Peterson E, Fischer PA, Podolin PL, Zijlstra M, Jaenisch R \& Peterson LB 1994 ß2-microglobulin-deficient NOD mice do not develop insulitis or diabetes. Diabetes 43 500-504. (doi:10.2337/diab.43.3.500)

You S, Alyanakian MA, Segovia B, Damotte D, Bluestone J, Bach JF \& Chatenoud L 2008 Immunoregulatory pathways controlling progression of autoimmunity in NOD mice. Annals of the New York Academy of Sciences 1150 300-310. (doi:10.1196/annals.1447.046)

Yuan R, El-Asady R, Liu K, Wang D, Drachenberg CB \& Hadley GA 2005 Critical role for $\mathrm{CD}_{103}{ }^{+} \mathrm{CD}^{+}$effectors in promoting tubular injury following allogeneic renal transplantation. Journal of Immunology $\mathbf{1 7 5}$ 2868-2879. (doi:10.4049/jimmunol.175.5.2868)

Zhang L, Moffatt-Bruce SD, Gaughan AA, Wang JJ, Rajab A \& Hadley GA 2009 An anti-CD103 immunotoxin promotes long-term survival of pancreatic islet allografts. American Journal of Transplantation 9 2012-2023. (doi:10.1111/j.1600-6143.2009.02735.x)

Received in final form 1 December 2014

Accepted 18 December 2014

Accepted Preprint published online 18 December 2014
(C) 2015 Society for Endocrinology Printed in Great Britain 